\title{
A STRATEGIC BIG DATA ANALYTICS FRAMEWORK TO PROVIDE OPPORTUNITIES FOR SMES
}

\author{
M. Willetts, A. S. Atkins, C. Stanier \\ School of Computing and Digital Technologies, Staffordshire University, College Road, \\ Stoke-on-Trent, ST4 2DE United Kingdom
}

\begin{abstract}
The paper outlines a holistic strategic framework to overcome the barriers of adoption to Big Data Analytics to support SMEs. Big Data adoption has continued to rapidly increase over the last five years, allowing firms that have successfully adopted the technology to analyse large volumes of complicated, unstructured data in a variety of formats, which has only recently been achievable because of advances in technology. Traditionally, Big Data is associated with large enterprises because of the perceived high entry costs of investing in the required infrastructure, software and data scientists to analyse the data. Due to their smaller size and limited resources, it is a common belief that Big Data is too large for SMEs to adopt and they do not have the volumes of data required to justify the investment. However, this paper demonstrates that there are cost-effective options available for SMEs to adopt including Google Analytics, social media and other Big Data as a Service solutions. This paper identifies the barriers encountered by SMEs in adopting Big Data Analytics and proposes a holistic strategic framework which will allow them to achieve a competitive advantage.
\end{abstract}

Keywords: Big Data, Big Data Analytics, SMEs, Big Data adoption, barriers to Big Data adoption.

\section{INTRODUCTION}

This paper examines the barriers that Small and Medium-Sized Enterprises (SMEs) encounter when adopting Big Data Analytics. The paper describes Big Data, explaining the types of Big Data and how it has been adopted by companies. A number of surveys have confirmed that companies are receiving benefits of Big Data technologies which include: enhanced productivity and growth, achieve transformational benefits, reduced operating costs, providing better products and services, align IT with business strategy, expansion of the company's capabilities, improved data management, improved data access and data [1]. Big Data Analytics are also defined to highlight the technologies, with examples provided of how Big Data Analytics has achieved measurable benefits for companies that have adopted it. SMEs represent $99.9 \%$ of all businesses in the UK and comprise $60 \%$ of employment. Therefore, a definition for SMEs is provided supported by statistics on their contribution to the national and global economy and SME's ability to adopt technology to ensure continued success. A survey of 15 manufacturing SMEs based in South Wales revealed that despite storing a wide variety of data only $46.7 \%$ were aware of Big Data Analytics of which $75 \%$ knew how they would use it and $60 \%$ stored less than 2TB of data [2], suggesting that there are a number of barriers to Big Data Analytics Adoption. The barriers to Big Data Analytics adoption are identified from a literature review and discussed. This paper is organised as follows: Section 2 gives the methodology. Section 3 discusses Big Data, Big Data Analytics and the barriers to adoption. Section 4 gives the conclusion and proposed future work.

\section{METHODOLOGY}

A literature search was undertaken to identify the barriers SMEs encounter when adopting Big Data Analytics. It is important to understand the current issues as a framework to assist SMEs in adopting Big Data Analytics would need to help them overcome these barriers. As the majority of Big Data literature relates to larger companies, literature relating to both SMEs and large companies was reviewed. It is considered that the barriers which impact large companies might also be applicable to SMEs including skills and the technology required although there may be some issues which are specific to SMEs. The two main search engines used in the literature review were Summon and Google Scholar. Thematic analysis was used to analyse the findings from the literature review. A thematic analysis is the process of identifying, analysing and reporting patterns and themes from qualitative datasets [3]. Braun and Clarke [3] describe the six phases of conducting a thematic analysis: 1 familiarisation with the data; 
2 generating initial codes; 3 searching for themes; 4 reviewing themes; 5 defining and naming themes; and 6 producing the report. Although thematic analysis is commonly associated with qualitative analysis of primary data including interview transcripts, it has been utilised to review the literature [4]. Two clearly documented examples were followed to conduct the analysis presented in this paper [3], [5]. For the First phase, familiarisation of data, 14 articles which discussed barriers to adoption were identified from the literature. To ensure familiarisation was achieved, the articles were appraised to ensure that the barriers were understood, reducing the risk of ambiguity and misinterpreting of their meaning. The final phase is to write a report, which provides an analysis of the themes, describing a story of the data, usually in the format of a research assignment or a dissertation [3], [5]. The outcome of the thematic analysis is presented in Section 3 of this paper.

\section{RESULTS}

This section discusses the findings from the literature review.

\subsection{Big Data}

The term Big Data has been widely used since 2011, defining data which is too large to be stored, processed and analysed using traditional business intelligence methods. Big Data is commonly associated with terabytes and petabytes of data [6], rather than smaller quantities. In 2013, it was stated that $90 \%$ of the world's data had been created within the last two years [7]. Data creation has continued to grow with 2.5 quintillion bytes (2 exabytes) of data created each day at the present pace [8]. IDC describe the Datasphere as the amount of data created, captured and replicated in a specific year [9] and expect the Datasphere to increase from 33 zettabytes in 2018 to 175 zettabytes in 2025 [10]. The large quantities of data generated on a daily basis can be partly be attributed to the growing number of smart devices and social media, each producing data per individual transaction made [11].

Big Data is defined as having a number of characteristics. Russom [12] stated that most definitions of Big Data focused on the volumes of data, however there are other important attributes. Russom [12] suggests that the three attributes that define big data are volume, velocity and variety. These are also known as the three $V s$ which were initially suggested as the challenges of data management [13] before being applied to Big Data. Pence [14] argues that complexity should be taken into account in additon to the three Vs, giving the example that personal Genomes are becoming cheaper in the United States and that although only $750 \mathrm{MB}$ is required to store an individual's DNA, storing DNA for the entire USA population would require 222 petabytes. If the objective was to analyse the genome for one person to find disease indicators, Big Data tools would be required due to the complexity of the interactions among the datasets. Complexity is also considered by other authors [15]-[18], suggesting that this should be a key characteristic of Big Data. It is proposed here that in understanding Big Data, Complexity is as important a concept as the three Vs. This study defines Big Data as: 'an umbrella term used to describe a wide range of technologies that capture, store, transform and analyse complex data sets which can be of a high volume, generated at a high velocity in a variety of formats'.

Big Data is generated from a range of sources. Mcafee and Brynjolfsson [19] state that many of the most important sources are relatively new, such as social network data. Saggi and Jain [20] define three categories of Big Data: machine-generated data which originates from sources including computer networks, sensors, satellites, audio, video and streaming; human-generated data in the form of identification data and social media content; and business-generated data in the form of transactional, corporate and government agencies' data. IoT (Internet of Things) and smart devices, including smartphones are one of the prominent drivers for Big Data, each typically contain digital sensors capable of capturing data, including cameras, audio recorders, compasses, gyroscopes, accelerometers and GPS locators [21], [22].

Additional Vs have been added by organisations within the technology industry. Veracity was introduced by IBM to highlight the unreliability of some sources of Big Data [23]. SAS introduced Variability as data flow in Big Data is often inconsistent, having periodic peaks and troughs [24]. An example of variability is a topic trending on Twitter, the volumes of data generated may be immense, with thousands or millions of tweets generated, whereas at other times, the same topic may have a much lower number of tweets. Value was added by Oracle [25] arguing that data has no use until its value is discovered. The discovery process may involve analysts and other business users asking questions, finding patterns, making assumptions and predicting behaviours. Other Vs have been added including Viability [26], Visualization [27] and Volatility [28]. The three Vs have been extended with additional Vs to produce Four Vs [29], Five Vs [25], [26], Six Vs [30], Seven Vs [27], [31], Nine Vs [32] and even Ten Vs [33]. Alsaig, Alagar 
and Ormandjieva [34] identified $19 \mathrm{Vs}$ in their review of published work. This has since been exceeded, with 42 [35] and 51 [36] Vs of Big Data, with 100 expected in the near future [35], [36]. None of the additional Vs appear to be used as consistently as the original three Vs. However, despite the popularity of the three Vs approach, it could be argued that this does not accurately represent Big Data.

Despite the perception that Big Data is expensive to adopt, there are options which do not require large upfront infrastructure costs. Big Data as a service (DaaS) is a Cloud-based solution which bridges the storage and processing gap [37]. Many leading vendors offer DaaS solutions including Microsoft's Hadoop on Azure, Google Cloud Big Table, Amazon AWS with Elastic MapReduce and Salesforce Analytics Cloud. These solutions provide the analytics, processing, storage and visualisation capabilities to transform data into insights.

Daniel [38] reported that a study undertaken by Unravel Data and Sapio Research revealed that despite $74 \%$ of the businesses surveyed having high expectations for Big Data, only $12 \%$ have achieved tangible benefits. The research revealed that approximately half of business leaders anticipate a lack of the skills and experience required to utilise Big Data technology correctly and unlock the benefits. Bradlow et al. [39] noted that although advances in the Big Data industries have led to accessible and inexpensive solutions, they do not provide a solution to other data issues, giving the example of a CRM system containing several decades worth of customer data. Some of this data is very old and may not reflect current customer requirements; therefore the company has a mixture of good and bad data and needs to deal with this challenge [39]. This suggests that are currently a number of barriers to adoption. Before Big Data sources were available for analysis, Business Intelligence tools were the primary focus of data analytics technologies. Business Intelligence has developed since the 1990s, in both the number of products and services available and the adoption of the technology [40]. However, Big Data Analytics have the capability to analyse large datasets in structured, unstructured and semi-structured formats.

\subsection{Big Data Analytics}

Big data analytics is the process of process of extracting insights from Big Data using a variety of software tools and techniques, not achievable through traditional Business Intelligence solutions. Mikalef et al. [41] identified that definitions of Big Data Analytics tended to focus on one of three categories: data and their defining characteristics; analytical procedures, tools and techniques; and the business value of presentation of the data analysis. Mikalef et al. [42, p. 262] state that a widely used definition of Big Data Analytics is: 'a new generation of technologies and architectures, designed to economically extract value from very large volumes of a wide variety of data, by enabling high velocity capture, discovery and/or analysis.'

The adoption of Big Data Analytics is increasing on a yearly basis. Columbus [43] reported that $59 \%$ of American companies had adopted Big Data Analytics in 2018, up from 53\% in 2017 [44] and 15\% in 2015. There are many benefits of Big Data Analytics reported in the literature, ranging from large multinational companies to SMEs. Ram, Zhang and Koronios [45, p. 223] report that Big Data Analytics can assist firms to: 'better exploit big data for improving customer satisfaction, managing supply chain risk, generating competitive intelligence, providing business real-time insights to help make important decisions and optimizing pricing if appropriately utilized'. Wielki [46] claims that the key value of Big Data platforms is to accelerate the time it takes to make decisions, giving organisations answers to questions in seconds rather than months. E. Ahmed et al. [47] state that one of the benefits the loT environment has provided through Big Data and analytics is the ability to extract valuable information from users, allowing them to predict future trends and detect fraud. IoT and enabling technologies including Cloud computing have facilitated the removal of data silos as traditionally, data is only considered useful for the domain it originated, however big datasets can now be combined.

A study of medium and large French companies [1] noted that $38 \%$ of the 200 company sample that had adopted Big Data technologies reported a variety of benefits achieved. Some of the most frequently recognised benefits from this survey include enhanced productivity and growth, achieving transformational benefits, reduced operating costs, providing better products and services, aligning IT with business strategy, expansion of the company's capabilities (for example the new skills gained and personnel recruited to support adoption of Big Data technologies), improved data management, improved data access and data provided in more usable formats [1]. Mathew [48] report that the average cost of unplanned downtime encountered by offshore oil and gas operators is $\$ 49$ million annually, potentially up to $\$ 88$ million. However, a study by Kimberlite found that by implementing a predictive, data-driven maintenance approach through the use of Big Data Analytics, operators have been able to reduce these costs by $36 \%$ as they are able to monitor equipment digitally and diagnose issues early [48]. 
Big Data Analytics is not limited to large enterprises. A survey of 500 European SMEs [49] revealed a number of advantages that Big Data Analytics has provided including effective internal and external knowledge management, creating organisational agility. These include the ability to sense opportunities and threats in the form of new products and services from competitors, identifying new opportunities including expanding into new international markets and adjusting to the technological environment to gain competitive advantage [49].

\subsection{Small and Medium Enterprises (SMEs)}

The UK government has set criteria which define the classification of a business and will be used for the purposes of this study. A small and medium sized enterprise (SME) is typically classified as a business with less than 250 employees [50]. The EU definition of an SME is similar to the UK's. The EU defines an SME as a company that has less than 250 employees, an annual turnover of up to $€ 50$ million and a maximum balance sheet total of $€ 43$ million [51]. A small company is one which meets at least two of the following criteria [52]: a turnover of less than $£ 10.2$ million; $£ 5.1$ million of less on its balance sheet; or employs less than 51 people. A medium-sized company is classified by meeting at least two of the following criteria: an annual turnover of $£ 36$ million or less; a maximum balance sheet total of $£ 18$ million; or a maximum of 250 employees. A company would be classified as large if it exceeded these criteria. Therefore, these will be used to define the categories of companies.

The World Bank [53] reported that SMEs account for $90 \%$ of all businesses and $50 \%$ of employment worldwide which highlights the importance of SMEs to the global economy. The Federation of Small Businesses [54] reported that at the start of 2019 SMEs accounted for $99.9 \%$ of all businesses in the UK (5.9 million). They also reported that SMEs comprise $60 \%$ of employment (16.6 million) and generate around half of the turnover in the UK's private sector (£2.2 trillion). This highlights the importance of SMEs in the UK, with the majority of the population working for an SME. Table 1 shows the comparison of the different types of UK company from the House of Parliament's annual report [55] with the number of each type of business, the percentage of workers they employ and their overall turnover.

Table 1. Private sector businesses in the UK by number of employees 2018 [55]

\begin{tabular}{|c|c|c|c|c|c|c|}
\hline \multicolumn{7}{|c|}{ Private sector businesses in the UK by number of employees, 2018} \\
\hline & Businesses & Employment & Turnover & Businesses & Employment & Turnover \\
\hline & $1000 \mathrm{~s}$ & $1000 s$ & $f$ billions & $\%$ & $\%$ & $\%$ \\
\hline No employees & 4,278 & 4,643 & 275 & $75 \%$ & $17 \%$ & $7 \%$ \\
\hline SMEs (0-250 employees) & 5,660 & 16,284 & 1,994 & $99.9 \%$ & $60 \%$ & $52 \%$ \\
\hline Of which: Micro (0-9 employees) & 5,416 & 8,802 & 808 & $96 \%$ & $33 \%$ & $21 \%$ \\
\hline Small (10-49 employees) & 210 & 4,083 & 590 & $4 \%$ & $15 \%$ & $15 \%$ \\
\hline Medium (50-249 employees) & 35 & 3,399 & 595 & $1 \%$ & $13 \%$ & $15 \%$ \\
\hline Large (250+ employees) & 8 & 10,743 & 1,868 & $0 \%$ & $40 \%$ & $48 \%$ \\
\hline Total, all businesses & 5,668 & 27,027 & 3,862 & $100 \%$ & $100 \%$ & $100 \%$ \\
\hline
\end{tabular}

However, the motivation to adopt emerging technology requires SMEs to be aware of the technology and identify a business need to adopt it. A study undertaken by Eze, Duan and Chen [56] using actornetwork theory suggests that an SME's decision to adopt emerging IT requires external stakeholders including IT experts, suppliers, consultants and government support agencies to align with the SME managers' interests. A later report in 2019 [22] by the OECD confirmed that Big Data adoption had increased with $33 \%$ of large firms, $19 \%$ of medium-sized enterprises and $10 \%$ of small companies using the technology in the EU. They also provided further insight into the adoption of Big Data: 'On average, one in ten SMEs (10-249 employees) in the European Union analyses big data, with a slight upward trend from $10 \%$ in 2016 to $12 \%$ in 2018 (against 33\% of large firms in 2018, up from 25\% in 2016). However, the adoption trends by SMEs have varied substantially across countries, advancing rapidly in some cases while decreasing in others.' [22, p. 17].

Kalan and Unalir [37] state that as the volume and velocity of data increases, there will be a point when the cost of using traditional databases to store, and process data will become too expensive. This suggests that SMEs that are currently storing and analysing data should investigate the feasibility of adopting Big Data Analytics. Schaeffer and Olson [57] state that volumes of data are continuing to rise because of the trends related to customer interaction, therefore SMEs need to work with Big Data. A study of 338 European SME's utilising social media and Big Data to innovate their business models, showed that business model innovation and strategy implementation results in more innovation leads 
and increased performance of the firms [58]. It was highlighted that literature on business model innovation and new technologies including social media and big data in non-IT and nontelecommunications companies is lacking and exploring big data-driven business models may become an important research domain.

A survey of 15 manufacturing SMEs based in South Wales revealed that despite storing a wide variety of data (supplier, manufacturing, product, sales, customer, financial and other data) only $46.7 \%$ were aware of Big Data Analytics of which $75 \%$ knew how they would use it [2]. $60 \%$ of the companies surveyed stored less than 2 TB of data and $93.3 \%$ stated that they did not have a problem managing the current amount of data they store. Therefore, awareness of Big Data Analytics and the volumes of data stored may be a barrier for adoption. Mattera [59] states that despite some Big Data tools being complex and too costly for SMEs, free tools such as Google Analytics are available which could be adopted by SMEs. Schemes such as Google Activate in Spain have been setup to help individuals learn the skills required to utilise Google Analytics, however it would be beneficial if these were extended to SMEs.

The challenges of SMEs adopting Big Data are documented in a number of studies. Coleman et al. [60] identified 14 problems or challenges SMEs may encounter when adopting data analytics or big data analytics including: lack of understanding, shortage of in-house data analytic expertise, lack of business cases and financial barriers. Some of these have been mentioned in other studies, which suggests that there may be more barriers to SMEs adopting big data analytics.

\subsection{Barriers to Big Data Analytics Adoption}

The literature review outlined in Section 2 identified 69 barriers to the adoption of Big Data Analytics. The barriers identified were recorded in a master data table to support thematic analysis. The thematic analysis facilitated the examination of the barriers, allowing similar concepts to be merged and themes to be identified. Table 2 illustrates the approach used, using 5 rows extracted from the master data table. The No. (number) column identifies the order in which the barriers were identified, for example Coleman et al. [60] was the first paper read and the barriers identified were number 1 to 14 . The barriers were then ranked depending on the number of times they appeared.

Table 2. Sample of Big Data Barriers identified from the literature search

\begin{tabular}{|c|c|c|c|c|c|c|c|c|c|c|c|c|c|}
\hline No & Barrier & [60] & [61] & [62] & [63] & [64] & [65] & [66] & [67] & [68] & [69] & [22] & Total \\
\hline 14 & Financial barriers & $\checkmark$ & & $\checkmark$ & $\checkmark$ & & $\checkmark$ & $\checkmark$ & $\checkmark$ & $\checkmark$ & $\checkmark$ & $\checkmark$ & 9 \\
\hline 1 & $\begin{array}{l}\text { Lack of } \\
\text { understanding }\end{array}$ & $\checkmark$ & $\checkmark$ & & $\checkmark$ & & $\checkmark$ & $\checkmark$ & & & & & 5 \\
\hline 28 & $\begin{array}{l}\text { Complexity of data } \\
\text { - e.g. unstructured } \\
\text { data }\end{array}$ & & & & & $\checkmark$ & & & $\checkmark$ & $\checkmark$ & & & 3 \\
\hline 3 & $\begin{array}{l}\text { Cultural barriers } \\
\text { and intrinsic } \\
\text { conservatism }\end{array}$ & $\checkmark$ & & & $\checkmark$ & $\checkmark$ & & & & & & & 3 \\
\hline 5 & $\begin{array}{l}\text { Bottlenecks in the } \\
\text { labour market }\end{array}$ & $\checkmark$ & $\checkmark$ & & & & & & & & & & 2 \\
\hline
\end{tabular}

Fig. 1 presents the barriers identified from the literature categorised under five headings, Technological, Human, Organisational, Environmental and Business. 


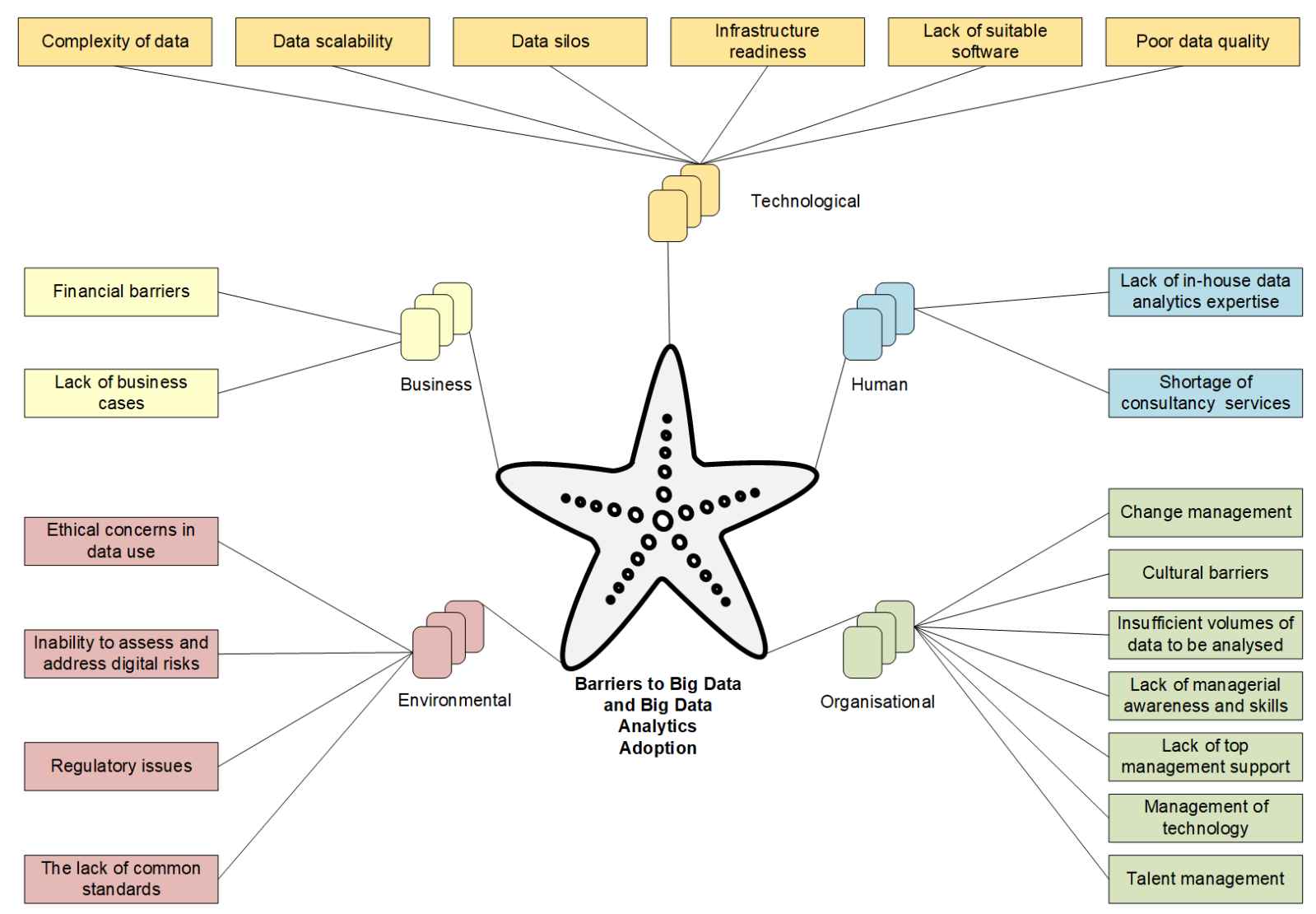

Figure 1. Barriers to the Adoption of Big Data and Big Data Technologies

\section{CONCLUSIONS}

Big Data is associated with complex datasets of one terabyte or larger [67] and complexity has been cited by a number of authors, therefore complexity is established as a key characteristic of Big Data. Big Data adoption is constantly increasing with $91.6 \%$ of leading companies accelerating the pace of their Big Data and Al investments [70] and businesses are now reporting measurable benefits from adopting Big Data [71]. Before Big Data Analytics, Business Intelligence was the primary focus of gaining insights from data. However, Business Intelligence is limited to processing structured, smaller and less complex datasets. In this paper, Big Data Analytics has been defined and a wide range of techniques have been identified, including affordable tools and technologies. Big Data Analytics has been adopted by both large enterprises and SMEs worldwide, with measurable benefits reported. This has shown that the technology justifies the investment if it is implemented and utilised correctly.

SMEs make a vital contribution to the worldwide economy, accounting for $90 \%$ of all businesses and $50 \%$ of employment [53]. Despite their small size, it is established that SMEs are able to adopt emerging technology [72] although they face a number of challenges and barriers. The current barriers to SMEs adopting Big Data Analytics have been identified from the literature review. The majority of these barriers could be grouped into themes, for example technological, data, knowledge and skills, data or other themes. Several barriers are very similar or relate to the same theme, suggesting that they could be merged together. In Fig. 1, the barriers have been shown, grouped into 5 categories. The next stage of the research is to develop a framework to support individual SMEs to identify whether a specific SME would benefit from adopting Big Data, to evaluate barriers to adoption and to develop a strategy to overcome these barriers.

\section{REFERENCES}

[1] E. Raguseo, "Big data technologies: An empirical investigation on their adoption, benefits and risks for companies," Int. J. Inf. Manage., vol. 38, no. 1, pp. 187-195, Feb. 2018. 
[2] A. Soroka, Y. Liu, L. Han, and M. S. Haleem, "Big Data Driven Customer Insights for SMEs in Redistributed Manufacturing," Procedia CIRP, vol. 63, pp. 692-697, Jan. 2017.

[3] V. Braun and V. Clarke, "Using Thematic Analysis in Psychology," Qual. Res. Psychol., vol. 3, pp. 77-101, Jan. 2006.

[4] V. Ward, A. House, and S. Hamer, "Developing a framework for transferring knowledge into action: a thematic analysis of the literature.," J. Health Serv. Res. Policy, vol. 14, no. 3, pp. 15664, Jul. 2009.

[5] M. Maguire and B. Delahunt, "Doing a Thematic Analysis: A Practical, Step-by-Step Guide for Learning and Teaching Scholars. *," 2017.

[6] R. Kitchin, "Big Data and Human Geography: Opportunities, Challenges and Risks," Dialogues Hum. Geogr., vol. 3, pp. 262-267, Dec. 2013.

[7] R. Jacobson, "2.5 quintillion bytes of data created every day. How does CPG \& Retail manage it? - IBM Consumer Products Industry Blog," IBM, 2013. [Online]. Available: https://www.ibm.com/blogs/insights-on-business/consumer-products/2-5-quintillion-bytes-ofdata-created-every-day-how-does-cpg-retail-manage-it/. [Accessed: 15-Dec-2019].

[8] B. Marr, "How Much Data Do We Create Every Day? The Mind-Blowing Stats Everyone Should Read," Forbes, $2018 . \quad$ [Online]. Available: https://www.forbes.com/sites/bernardmarr/2018/05/21/how-much-data-do-we-create-everyday-the-mind-blowing-stats-everyone-should-read/\#3f26597f60ba. [Accessed: 15-Dec-2019].

[9] IDC, "Global DataSphere," IDC. [Online]. Available: https://www.idc.com/getdoc.jsp?containerld=IDC_P38353. [Accessed: 15-Dec-2019].

[10] T. Coughlin, "175 Zettabytes By 2025," Forbes, 2018. [Online]. Available: https://www.forbes.com/sites/tomcoughlin/2018/11/27/175-zettabytes-by2025/\#52b570415459. [Accessed: 15-Dec-2019].

[11] B. Marr, "How Much Data Is There In the World?," 2019. [Online]. Available: https://www.bernardmarr.com/default.asp?contentID=1846. [Accessed: 15-Dec-2019].

[12] P. Russom, "Big data analytics," TDWI best Pract. report, fourth Quart., vol. 19, no. 4, pp. 1-34, 2011.

[13] D. Laney, "3D Data Management: Controlling Data Volume, Velocity, and Variety," 2001.

[14] H. E. Pence, "What is Big Data and Why is it Important?," J. Educ. Technol. Syst., vol. 43, no. 2, pp. 159-171, Dec. 2015.

[15] N. Kshetri, "The emerging role of Big Data in key development issues: Opportunities, challenges, and concerns," 2014.

[16] A. Gani, A. Siddiqa, S. Shamshirband, and F. Hanum, "A survey on indexing techniques for big data: taxonomy and performance evaluation," Knowl. Inf. Syst., vol. 46, no. 2, pp. 241-284, 2016.

[17] F. Amalina et al., "Blending Big Data Analytics: Review on Challenges and a Recent Study," IEEE Access, pp. 1-1, 2019.

[18] A. Katal, M. Wazid, and R. H. Goudar, "Big data: Issues, challenges, tools and Good practices," in 2013 6th International Conference on Contemporary Computing, IC3 2013, 2013, pp. 404409.

[19] A. Mcafee and E. Brynjolfsson, "Spotlight on Big Data: The Management Revolution," Harvard Business Review, no. October, pp. 1-9, 2012.

[20] M. K. Saggi and S. Jain, "A survey towards an integration of big data analytics to big insights for value-creation," Inf. Process. Manag., vol. 54, no. 5, pp. 758-790, Sep. 2018.

[21] A. De Mauro, M. Greco, and M. Grimaldi, "A formal definition of Big Data based on its essential features," Libr. Rev., vol. 65, no. 3, pp. 122-135, Apr. 2016.

[22] M. Bianchini and V. Michalkova, "OECD SME and Entrepreneurship Papers No. 15 Data Analytics in SMEs: Trends and Policies," 2019.

[23] J. Palfreyman, "Big Data - Vexed by Veracity? - IBM Government Industry Blog," 2013. [Online]. 
Available: $\quad$ https://www.ibm.com/blogs/insights-on-business/government/big-data-vexed-byveracity/. [Accessed: 08-Jul-2019].

[24] SAS, "What Is Big Data? | SAS UK." [Online]. Available: https://www.sas.com/en_gb/insights/bigdata/what-is-big-data.html. [Accessed: 08-Jul-2019].

[25] Oracle, "What Is Big Data?" [Online]. Available: https://www.oracle.com/uk/big-data/guide/whatis-big-data.html\#link3. [Accessed: 27-Oct-2019].

[26] N. Biehn, "The Missing V's in Big Data: Viability and Value | WIRED," 2013. [Online]. Available: https://www.wired.com/insights/2013/05/the-missing-vs-in-big-data-viability-and-value/. [Accessed: 15-Nov-2019].

[27] U. Sivarajah, M. M. Kamal, Z. Irani, and V. Weerakkody, "Critical analysis of Big Data challenges and analytical methods," J. Bus. Res., vol. 70, pp. 263-286, Jan. 2017.

[28] M. A. U. D. Khan, M. F. Uddin, and N. Gupta, "Seven V's of Big Data understanding Big Data to extract value," in Proceedings of the 2014 Zone 1 Conference of the American Society for Engineering Education - "Engineering Education: Industry Involvement and Interdisciplinary Trends", ASEE Zone 1 2014, 2014.

[29] A. Abbasi, S. Sarker, and R. H. L. Chiang, "Big Data Research in Information Systems: Toward an Inclusive Research Agenda.," J. Assoc. Inf. Syst., vol. 17, no. 2, pp. i-xxxii, Feb. 2016.

[30] J. Andreu, C. Poon, R. Merrifield, S. Wong, and G.-Z. Yang, "Big Data for Health," IEEE J. Biomed. Heal. informatics, vol. 19, Jul. 2015.

[31] J. J. J. M. Seddon and W. L. Currie, "A model for unpacking big data analytics in high-frequency trading," J. Bus. Res., vol. 70, pp. 300-307, Jan. 2017.

[32] S. S. Owais and N. S. Hussein, "Extract Five Categories CPIVW from the 9V's Characteristics of the Big Data," 2016.

[33] G. Firican, "The $10 \mathrm{Vs}$ of Big Data," 2017. [Online]. Available: https://tdwi.org/articles/2017/02/08/10-vs-of-big-data.aspx. [Accessed: 14-Nov-2019].

[34] A. Alsaig, V. Alagar, and O. Ormandjieva, "A Critical Analysis of the V-Model of Big Data," in Proceedings - 17th IEEE International Conference on Trust, Security and Privacy in Computing and Communications and 12th IEEE International Conference on Big Data Science and Engineering, Trustcom/BigDataSE 2018, 2018, pp. 1809-1813.

[35] T. Shafer, "The 42 V's of Big Data and Data Science," KDnuggets, 2017. [Online]. Available: https://www.kdnuggets.com/2017/04/42-vs-big-data-data-science.html. [Accessed: 05-Dec2019].

[36] N. Khan, A. Naim, M. R. Hussain, Q. N. Naveed, N. Ahmad, and S. Qamar, "The 51 V's of Big Data: Survey, technologies, characteristics, opportunities, issues and challenges," in ACM International Conference Proceeding Series, 2019, vol. Part F1481, pp. 19-24.

[37] R. S. Kalan and M. O. Unalir, "Leveraging big data technology for small and medium-sized enterprises (SMEs)," in 2016 6th International Conference on Computer and Knowledge Engineering (ICCKE), 2016, pp. 1-6.

[38] E. Daniel, "Just 12\% of businesses experiencing benefits of big data, study finds," Verdict, 2018. [Online]. Available: https://www.verdict.co.uk/big-data-in-business/. [Accessed: 28-Nov-2019].

[39] E. T. Bradlow, M. Gangwar, P. Kopalle, and S. Voleti, "The Role of Big Data and Predictive Analytics in Retailing," J. Retail., vol. 93, no. 1, pp. 79-95, 2017.

[40] S. Chaudhuri, U. Dayal, and V. Narasayya, "An overview of business intelligence technology," Communications of the ACM, vol. 54, no. 8. pp. 88-98, Aug-2011.

[41] P. Mikalef, I. O. Pappas, J. Krogstie, and M. Giannakos, "Big data analytics capabilities: a systematic literature review and research agenda," Inf. Syst. E-bus. Manag., vol. 16, no. 3, pp. 547-578, Aug. 2018.

[42] P. Mikalef, M. Boura, G. Lekakos, and J. Krogstie, "Big data analytics and firm performance: Findings from a mixed-method approach," J. Bus. Res., vol. 98, pp. 261-276, 2019.

[43] L. Columbus, "Big Data Analytics Adoption Soared In The Enterprise In 2018," 2018. [Online]. 
Available: https://www.forbes.com/sites/louiscolumbus/2018/12/23/big-data-analytics-adoptionsoared-in-the-enterprise-in-2018/\#6b7df2d8332f. [Accessed: 16-Nov-2019].

[44] L. Columbus, "53\% Of Companies Are Adopting Big Data Analytics," 2017. [Online]. Available: https://www.forbes.com/sites/louiscolumbus/2017/12/24/53-of-companies-are-adopting-bigdata-analytics/\#183b888939a1. [Accessed: 16-Nov-2019].

[45] J. Ram, C. Zhang, and A. Koronios, "The Implications of Big Data Analytics on Business Intelligence: A Qualitative Study in China," Procedia Comput. Sci., vol. 87, pp. 221-226, Jan. 2016.

[46] J. Wielki, "Implementation of the Big Data concept in organizations - Possibilities, impediments and challenges," Proc. Fed. Conf. Comput. Sci. Inf. Syst., 2013.

[47] E. Ahmed et al., "The role of big data analytics in Internet of Things," Comput. Networks, vol. 129, pp. 459-471, Dec. 2017.

[48] B. Mathew, "How Big Data is reducing costs and improving performance in the upstream industry," 2016. [Online]. Available: https://www.worldoil.com/news/2016/12/13/how-big-data-isreducing-costs-and-improving-performance-in-the-upstream-industry. [Accessed: 05-Dec2019].

[49] N. Côrte-Real, T. Oliveira, and P. Ruivo, "Assessing business value of Big Data Analytics in European firms," J. Bus. Res., vol. 70, pp. 379-390, Jan. 2017.

[50] M. Ward and C. Rhodes, "Small businesses and the UK economy," 2014.

[51] Eurostat, "Small and medium-sized enterprises (SMEs)." [Online]. Available: https://ec.europa.eu/eurostat/web/structural-business-statistics/structural-businessstatistics/sme. [Accessed: 15-Nov-2019].

[52] GOV.UK, "Prepare annual accounts for a private limited company: Micro-entities, small and dormant companies." [Online]. Available: https://www.gov.uk/annual-accounts/microentitiessmall-and-dormant-companies. [Accessed: 15-Nov-2019].

[53] The World Bank, "Small and Medium Enterprises (SMEs) Finance," The World Bank, 2019. [Online]. Available: https://www.worldbank.org/en/topic/smefinance. [Accessed: 01-Dec-2019].

[54] Federation of Small Businesses, "UK Small Business Statistics," 2019. [Online]. Available: https://www.fsb.org.uk/media-centre/small-business-statistics. [Accessed: 15-Nov-2019].

[55] C. Rhodes, "Business statistics," 2018.

[56] S. C. Eze, Y. Duan, and H. Chen, "Examining emerging ICT's adoption in SMEs from a dynamic process approach," Inf. Technol. People, vol. 27, no. 1, pp. 63-82, Feb. 2014.

[57] D. M. Schaeffer and P. C. Olson, "Big Data Options For Small And Medium Enterprises," Rev. Bus. Inf. Syst., vol. 18, no. 1, p. 41, Apr. 2014.

[58] H. Bouwman, S. Nikou, F. J. Molina-Castillo, and M. de Reuver, "The impact of digitalization on business models," Digit. Policy, Regul. Gov., vol. 20, no. 2, pp. 105-124, Mar. 2018.

[59] M. Mattera, "SMEs transformation through usage and understanding of big data case study: Spanish restaurant industry," in 2018 IEEE 3rd International Conference on Big Data Analysis (ICBDA), 2018, pp. 186-189.

[60] S. Coleman, R. Göb, G. Manco, A. Pievatolo, X. Tort-Martorell, and M. S. Reis, "How Can SMEs Benefit from Big Data? Challenges and a Path Forward," Qual. Reliab. Eng. Int., vol. 32, no. 6, pp. 2151-2164, Oct. 2016.

[61] F. Sejahtera, W. Wang, M. Indulska, and S. Sadiq, "Enablers and Inhibitors of Effective Use of Big Data: Insights From a Case Study," in Proceedings of the 22nd Pacific Asia Conference on Information Systems, 2018, pp. 27-32.

[62] Z. Polkowski and M. Nycz, "Big Data Applications in SMEs," Sci. Bull. - Econ. Sci., vol. 15, no. 3, pp. 13-24, 2016.

[63] M. Iqbal, S. H. A. Kazmi, A. Manzoor, A. R. Soomrani, S. H. Butt, and K. A. Shaikh, "A study of big data for business growth in SMEs: Opportunities \& challenges," in 2018 International Conference on Computing, Mathematics and Engineering Technologies: Invent, Innovate and 
Integrate for Socioeconomic Development, iCoMET 2018 - Proceedings, 2018, vol. 2018-Janua, pp. 1-7.

[64] A. Alharthi, V. Krotov, and M. Bowman, "Addressing barriers to big data," Bus. Horiz., vol. 60, no. 3, pp. 285-292, May 2017.

[65] A. Olufemi, "Considerations for the Adoption of Cloud-based Big Data Analytics in Small Business Enterprises," Electron. J. Inf. Syst. Eval., vol. 21, no. 2, pp. 63-79, May 2018.

[66] W. Noonpakdee, A. Phothichai, and T. Khunkornsiri, "Big data implementation for small and medium enterprises," in 2018 27th Wireless and Optical Communication Conference, WOCC 2018, 2018, pp. 1-5.

[67] I. Lee, "Big data: Dimensions, evolution, impacts, and challenges," Bus. Horiz., vol. 60, no. 3, pp. 293-303, May 2017.

[68] C. O'Connor and S. Kelly, "Facilitating knowledge management through filtered big data: SME competitiveness in an agri-food sector," J. Knowl. Manag., vol. 21, no. 1, pp. 156-179, Feb. 2017.

[69] D. Arunachalam, N. Kumar, and J. P. Kawalek, "Understanding big data analytics capabilities in supply chain management: Unravelling the issues, challenges and implications for practice," Transp. Res. Part E Logist. Transp. Rev., 2018.

[70] NewVantage Partners, "Big Data and Al Executive Survey 2019: Executive Summary of Findings," 2019.

[71] NewVantage Partners, "Big Data Executive Survey 2017: Executive Summary of Findings," 2017.

[72] J. W. Velthuijsen, B. Yıldırım, G. Kramer, and R. Schmidl, "Innovation and Digital Transformation: How do European SMEs perform?," 2018. 